\title{
Investigation of variable aeration of monodisperse mixtures: implications for pyroclastic density currents
}

\author{
Gregory M. Smith ${ }^{1}$ (D) $\cdot$ Rebecca Williams ${ }^{1} \cdot$ Pete J. Rowley $^{1,2} \cdot$ Daniel R. Parsons $^{3}$
}

Received: 10 March 2018 / Accepted: 9 July 2018 / Published online: 30 July 2018

(C) The Author(s) 2018

\begin{abstract}
The high mobility of dense pyroclastic density currents (PDCs) is commonly attributed to high gas pore pressures. However, the influence of spatial and temporal variations in pore pressure within PDCs has yet to be investigated. Theory suggests that variability in the fluidisation and aeration of a current will have a significant control on PDC flow and deposition. In this study, the effect of spatially heterogeneous gas pore pressures in experimental PDCs was investigated. Sustained, unsteady granular currents were released into a flume channel where the injection of gas through the channel base was controlled to create spatial variations in aeration. Maximum current front velocity results from high degrees of aeration proximal to the source, rather than lower sustained aeration along the whole flume channel. However, moderate aeration (i.e. $\sim 0.5$ minimum static fluidisation velocity $\left(U_{\mathrm{mf}_{-} \mathrm{st}}\right)$ ) sustained throughout the propagation length of a current results in greater runout distances than currents which are closer to fluidisation (i.e. $0.9 U_{\text {mf_st }}$ ) near to source, then de-aerating distally. Additionally, although all aerated currents are sensitive to channel base slope angle, the runout distance of those currents where aeration is sustained throughout their lengths increases by up to $54 \%$ with an increase of slope from $2^{\circ}$ to $4^{\circ}$. Deposit morphologies a primarily controlled by the spatial differences in aeration, where there is a large decrease in aeration the current forms a thick depositional wedge. Sustained gas-aerated granular currents are observed to be spontaneously unsteady, with internal sediment waves travelling at different velocities.
\end{abstract}

Keywords Pyroclastic density current $\cdot$ Aerated currents $\cdot$ Flume $\cdot$ Fluidisation $\cdot$ Pore pressure $\cdot$ Slope angle

\section{Introduction}

Pyroclastic density currents (PDCs) are hazardous flows of hot, density-driven mixtures of gas and volcanic particles generated during explosive volcanic eruptions, or from the collapse of

Editorial responsibility: R.J. Brown

Electronic supplementary material The online version of this article (https://doi.org/10.1007/s00445-018-1241-1) contains supplementary material, which is available to authorized users.

Gregory M. Smith

Gregory.Smith@2016.hull.ac.uk

1 School of Environmental Sciences, University of Hull, Hull HU6 $7 \mathrm{RX}, \mathrm{UK}$

2 School of Earth and Environmental Sciences, University of Portsmouth, Burnaby Road, Portsmouth PO1 3 QL, UK

3 Energy and Environment Institute, University of Hull, Hull HU6 7RX, UK lava domes (e.g. Yamamoto et al. 1993; Branney and Kokelaar 2002; Cas et al. 2011). They are capable of depositing large ignimbrite sheets, which can exhibit a variety of sedimentary structures and grading patterns (e.g. Rowley et al. 1985; Wilson 1985; Fierstein and Hildreth 1992; Branney and Kokelaar 2002; Brown and Branney 2004; Sarocchi et al. 2011; Douillet et al. 2013; Brand et al. 2016). As evidenced by the occurrence of these deposits far from sources, PDCs can achieve long runout distances on slopes shallower than the angle of rest of granular materials, even at low volumes (e.g. Druitt et al. 2002; Cas et al. 2011; Roche et al. 2016). Explanations for these long runout distances vary according to whether the current in question is envisaged as dilute or dense (cf. Dade and Huppert 1996; Wilson 1997). PDC transport encompasses a spectrum whose end-members can be defined as either fully dilute or granular-fluid currents (Walker 1983; Druitt 1992; Branney and Kokelaar 2002; Burgissier and Bergantz 2002; Breard and Lube 2016). In the first type, clast interactions are negligible, and support and transport of the pyroclasts are dominated by fluid turbulence at all levels in the 
current (Andrews and Manga 2011, 2012). In contrast, in highly concentrated granular-fluid based currents, particle interactions are important and turbulence is dampened (e.g. Savage and Hutter 1989; Iverson 1997; Branney and Kokelaar 2002). Here, the differential motion between the interstitial gas and solid particles is able to generate pore fluid pressure due to the relatively low permeability of the gas-particle mixture (Druitt et al. 2007; Montserrat et al. 2012; Roche 2012). An intermediate regime has also recently been defined, characterised by mesoscale turbulence clusters (Breard et al. 2016), which couple the dilute and dense regions of a PDC.

Where dense PDCs are concerned, their high mobility is commonly attributed to the influence of fluidisation of the current's particles caused by high, long-lived gas pore pressures (Sparks 1976; Wilson 1980; Druitt et al. 2007; Roche 2012; Gueugneau et al. 2017; Breard et al. 2018). These high gas pore pressures fundamentally result from relative motion between settling particles and ascending fluid and can be produced through various processes including (i) bulk selffluidisation (McTaggart 1960; Wilson and Walker 1982), (ii) grain self-fluidisation (Fenner 1923; Brown 1962; Sparks 1978), (iii) sedimentation fluidisation/hindered settling (Druitt 1995; Chédeville and Roche 2014), and (iv) decompression fluidisation (Druitt and Sparks 1982); see Wilson (1980) and Branney and Kokelaar (2002) for reviews.

As gas pore pressures within a gas-particle mixture increase, inter-particle stresses are reduced as the particles become fluidised (Gibilaro et al. 2007; Roche et al. 2010). Fluidisation of a granular material is defined as the condition where a vertical drag force exerted by a gas flux is strong enough to support the weight of the particles, resulting in apparent friction reduction and fluid-like behaviour (Druitt et al. 2007; Gilbertson et al. 2008). The gas velocity at which this occurs is known as the minimum fluidisation velocity $\left(U_{\mathrm{mf}}\right)$. Where there is a gas flux through a sediment which is less than $U_{\mathrm{mf}}$, then that sediment is partially fluidised and is often termed aerated.

The gas pore pressure decreases over time during flow, once there is little or no relative gas-particle motion, according to: $t_{\mathrm{d}} \propto H^{2} / D$

where $H$ is the bed height and $D$ is the diffusion coefficient of the gas (Roche 2012). PDCs are dominated by finer-grained particles, which confer a greater surface area than coarse particles, conveying low mixture permeability (Druitt et al. 2007; Roche 2012). PDCs are therefore thought to sustain high pore pressures for longer, resulting in greater mobility than their unfluidized "dry" granular counterparts (i.e. rockfalls).

The detailed fluid dynamics and processes involved with pore pressure in PDCs are elusive due to the significant challenge of obtaining measurements. Moreover, the observation of depositional processes is challenging as the basal parts of PDCs are hidden by an overriding ash cloud. Scaled, physical modelling can provide a direct way to simulate and quantify the behaviour of several processes, which take place in PDCs under controlled, variable conditions, as well as creating easily accessible analogous deposits.

Dam break-type experimental currents aimed at representing simplified, uniformly permeable, dense PDCs have attempted to model fluidisation processes by fluidising particles before release into a flume (Roche et al. 2002; Roche et al. 2004). These demonstrate that fluidisation has an important effect on runout distance. However, rapid pore pressure diffusion results in shorter runout distances and thinner deposits than might be expected in full scale currents (e.g. Roche et al. 2004; Girolami et al. 2008; Roche et al. 2010; Roche 2012; Montserrat et al. 2016). This is because while the material permeability in both natural and experimental currents is similar (with experimental currents being somewhat fines depleted in comparison to natural PDCs), experimental currents are much thinner than their natural counterparts, resulting in more rapid loss of pore pressure. Experiments have demonstrated that the degree of fluidisation is also important in contributing to substrate entrainment and the resulting transport capacity of fluidised currents (Roche et al. 2013). Early work on the sustained fluidisation of granular currents by injection of air at the base of the current (Eames and Gilbertson 2000) was not focused on replicating the behaviour of PDCs in particular, but did demonstrate that this was a valid method of preventing rapid pore pressure diffusion in granular currents. Rowley et al. (2014) reproduced the long-lived high gas pore pressures of sustained PDCs using an experimental flume, which fed a gas flux through a porous basal plate to simulate long pore pressure diffusion timescales in natural, thicker currents. This resulted in much greater runout distances than unaerated or initially fluidised currents. However, these experiments were unable to explore defluidisation due to the constant uniform gas supply along the flume length.

Natural PDCs are unlikely to be homogenously aerated (Gueugneau et al. 2017) and are inherently heterogeneous due to factors, such as source unsteadiness and segregation of particles (Branney and Kokelaar 2002), which can cause spatial variability in factors controlling $U_{\mathrm{mf}}$, such as bulk density. Hence, different pore pressure generation mechanisms may be operating in different areas of the PDC at once. For example, fluidisation due to the exsolution of volatiles from juvenile clasts (Sparks 1978; Wilson 1980) could be dominant in one part of the PDC and fluidisation from hindered settling of depositing particles (Druitt 1995; Girolami et al. 2008) or autofluidisation from particles settling into substrate interstices (Chédeville and Roche 2014) dominant in another. It is important, then, to understand the impacts of variable fluidisation on such currents.

Here, we present experiments using a flume tank which we set up to investigate the effect of spatially variable aeration on a sustained granular current at different slope angles. The flume allows the simulation of various pore pressures and states of aeration in the same current down the channel. This allows the currents to stabilise and propagate for a controlled 
distance before de-aeration occurs. We report how this spatially variable aeration, as well as the channel slope angle, affects the current runout distance, frontal velocity, and characteristics of the subsequent deposit. It should be noted that our work attempts to simulate the fact that PDCs are fluidised/aerated to some degree for long periods of time, rather than attempting to replicate a particular mechanism of fluidisation.

\section{Methods}

The experimental flume is shown in Fig. 1. A hopper supplies the particles to a $0.15-\mathrm{m}$ wide, $3.0-\mathrm{m}$ long, channel through a horizontal lock gate $0.64 \mathrm{~m}$ above the channel base. The base of the flume sits above three 1.0-m long chambers, each with an independently controlled compressed air supply, which feeds into the flume through a porous plate. The flume channel can be tilted up to $10^{\circ}$ from horizontal.

The air-supply plumbing allows a gas flux to be fed through the base of the flume, producing sustained aeration of the current. In such thin $(<30 \mathrm{~mm})$, rapidly degassing laboratory currents, this enables us to simulate the long-lived high gas pore pressures that characterise thicker PDCs (Rowley et al. 2014). An important aspect of this flume is that the gas flux for each of the three chambers may be controlled individually, allowing the simulation of spatially variable magnitudes of pore pressures.

The experiments were performed using spherical soda lime ballotini with grain sizes of 45-90 $\mu \mathrm{m}$ (average $D_{32}=$ $63.4 \mu \mathrm{m}$ calculated from six samples across the material batch, see Table 3 in Appendix A for grain size information), similar to the type of particles used in previous experimental granular currents (e.g. Roche et al. 2004; Rowley et al. 2014; Montserrat et al. 2016). $D_{32}$, or the Sauter mean diameter, can be expressed as

$D_{32}=\frac{1}{\sum \frac{x_{i}}{d_{i}}}$

Fig. 1 A longitudinal section view of the experimental flume where $x_{\mathrm{i}}$ is the weight fraction of particles of size $d_{\mathrm{i}}$. In line with Breard et al. (2018), $D_{32}$ was given here because it exerts some control on current permeability (Li and Ma 2011).

These grain sizes assign the ballotini to group A of Geldart (1973), which are those materials which expand homogenously above $U_{\mathrm{mf}}$ until bubbles form. As PDCs contain dominantly group A particles, this allows dynamic similarity between the natural and experimental currents (Roche 2012). Ballotini grains have a stated solid density of $2500 \mathrm{~kg} /$ $\mathrm{m}^{3}$ and a repose angle measured by shear box to be $26^{\circ}$.

The experiments were recorded using high-speed video at 200 frames per second. This video recorded a side-wall area of the channel across the first and second chambers, allowing the calculation of variations in the current front velocity. Velocities were calculated at 0.1-m intervals, from highspeed video which recorded the currents across a section of the flume from 0.8 to $1.7 \mathrm{~m}$. All runout measurements are given as a distance from the headwall of the flume.

The variables experimentally controlled, and thus investigated, in these experiments are as follows: (i) the gas flux supplied through the base in each of the three sections of the channel and (ii) the slope angle of the channel. The slope angles examined were $2^{\circ}$ and $4^{\circ}$. A range of gas supply velocities were used to vary the aeration state of the particles, all of which were below $U_{\mathrm{mf}}$ as complete fluidisation would result in non-deposition. Static piles of particles used in these experiments achieve static minimum fluidisation $\left(U_{\mathrm{mf} \text { st }}\right)$ with a vertical gas velocity of $0.83 \mathrm{~cm} / \mathrm{s}$. This is comparable to Roche (2012), who used the same 45-90- $\mu \mathrm{m}$ glass ballotini. Because our fluidisation state was measured in a static pile, we explicitly use $U_{\mathrm{mf} \text { st }}$ rather than $U_{\mathrm{mf}}$ in order to denote the origin of this value in these experiments. In a moving (i.e. shearing) current, $U_{\mathrm{mf}}$ will be higher than $U_{\mathrm{mf} \text { st }}$ because dilatancy would be anticipated, and therefore, an increase in porosity should be observed.

Aeration states were varied from $0 \mathrm{~cm} / \mathrm{s}$ (non-aerated) through various levels of aeration to a maximum of $0.77 \mathrm{~cm} / \mathrm{s}$. Table 1 shows the gas velocities used as a proportion of $U_{\text {mf_st }}$ across the

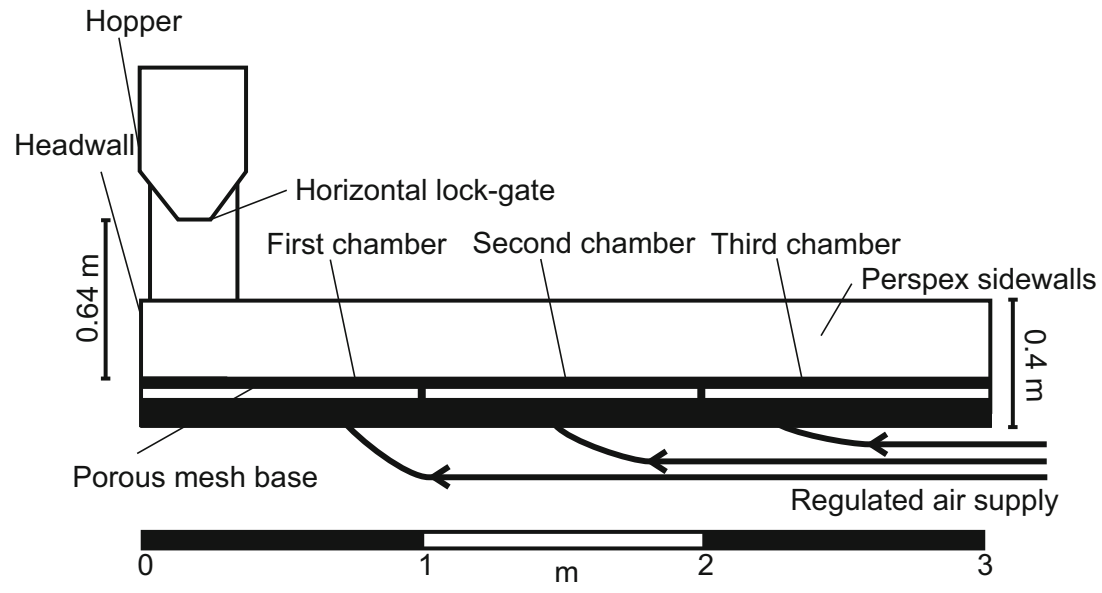


Table 1 Conversion of gas velocities used in the experiments into proportions of $U_{\text {mf_st }}$ $(0.83 \mathrm{~cm} / \mathrm{s})$

\begin{tabular}{ll}
\hline $\begin{array}{l}\text { Proportion } \\
\text { of } U_{\mathrm{mf} s \mathrm{st}}\end{array}$ & $\begin{array}{l}\text { Gas velocity } \\
(\mathrm{cm} / \mathrm{s})\end{array}$ \\
\hline 1.00 & 0.83 \\
0.93 & 0.77 \\
0.66 & 0.55 \\
0.53 & 0.44 \\
0.46 & 0.38 \\
0.4 & 0.33 \\
\hline
\end{tabular}

experimental set. The mass of particles comprising the currents (the "charge") was kept constant, at $10 \mathrm{~kg}$ for each run.

\section{Results}

\section{Runout distance and current front velocity}

Runout distance is markedly affected by variations in the aeration states. For a given slope angle, if the aeration states are the same in all three chambers, then increasing the gas flux causes runout distances to increase. The measurable limit for runout distance in these experiments is $3 \mathrm{~m}$ (i.e. when the current exits the flume) (Fig. 2). In this work, when describing the aeration state of the flume as a whole, the gas velocities of each chamber are listed as proportions of $U_{\mathrm{mf} s t}$, in increasing distance from the headwall. For example, an aeration state of 0.93-0.93-0 means that the first two chambers are aerated at $0.93 U_{\text {mf_st }}$ and the third chamber is unaerated.

Where aeration state is decreased along the length of the flume, greater runout distances are still correlated with greater aeration states. At a high aeration state in the first chamber, behaviour of the current is dependent on the aeration state in the second chamber. For example, Fig. 2 demonstrates how 0.93-0.93-0 $U_{\text {mf_st }}$ currents have greater runout distances than 0.93-0.66-0 $U_{\text {mf st }}$ currents which in turn have greater runout distances than 0.93-0-0 $U_{\mathrm{mf} \text { st }}$ currents. At a lower aeration state in the first chamber, the runout distance seems to be dependent on the aeration state in the third chamber. For example, in Fig. 2, 0.66-0.53-0.4 $U_{\mathrm{mf} \text { st }}$ currents have greater runout distances than $0.66-0.66-0 \bar{U}_{\mathrm{mf} \text { st }}$ currents and 0.53 $0.4-0.4 U_{\mathrm{mf} \text { st }}$ currents have greater runout distances than 0.53-0.53-0 $\bar{U}_{\text {mf st }}$ currents.

The current front velocity is also dependent on the aeration state. Current front velocity does not exceed $1.5 \mathrm{~m} / \mathrm{s}$ (Fig. 3). This is considerably less than the calculated free fall velocity $(2 g h)^{1 / 2}=3.5 \mathrm{~m} / \mathrm{s}$, where $g$ is the gravitational acceleration and $h$ is the $0.64-\mathrm{m}$ drop height; however, by the interval at which velocity is measured, the currents have travelled $0.8 \mathrm{~m}$ and will also have lost energy upon impingement. Generally, regardless of the aeration state in the first
Fig. 2 Runout distances for various aeration states on different slope angles. Results are shown as profiles of the actual deposits formed. Aeration states of the three chambers are given on the y-axis. Dividing lines show the transition points between the three chambers. Flume length is $300 \mathrm{~cm}$. Vertical scale $=$ horizontal scale

or second chamber, the current front velocity decreases over the measured interval (Fig. 3). Higher aeration states, however, sustain higher current front velocities across greater distances. Also, where the aeration state decreases from the first chamber into the second, the current front velocity is not always immediately affected and may even temporarily increase (Fig. 3). Overall, the highest current front velocities across the whole $0.9-\mathrm{m}$ interval are always found in the 0.93-0.93-0 $U_{\text {mf_st }}$ aeration state.

\section{Slope angle and runout distance}

For a given aeration state, increasing the slope angle acts to increase the runout distance of the current (Fig. 2). However, the magnitude of the increase is dependent on the overall aeration state of the current; large increases in runout distance from increased slope angle only occur where the current is uniformly aerated or there is a small decrease in gas flux between chambers. For example, as slope increases from 2 to $4^{\circ}, 0.4-0.4-0.4 U_{\mathrm{mf} \text { st }}, 0.46-0.46-0.46 U_{\mathrm{mf} \text { st }}$, and 0.530.4-0.4 $U_{\mathrm{mf} \text { st }}$ currents see increases in runout distances from 1.3 to $2 \mathrm{~m}(54 \%), 2$ to $3+\mathrm{m}(\geq 50 \%)$, and 2 to $2.43 \mathrm{~m}(22 \%)$, respectively. Whether this is also the case for higher and uniformly aerated states $\left(0.53-0.53-0.53 U_{\text {mf_st }}\right.$ and $0.66-0.66-$ $\left.0.66 U_{\mathrm{mf} s t}\right)$, it is not clear as both slope angles resulted in maximum current runout (i.e. $3+\mathrm{m}$ ).

The effect of increasing slope angle on increasing runout distance is subdued when currents are allowed to de-aerate more quickly. For example, currents of 0.93-0.66-0 $U_{\mathrm{mf} \text { st }}$ conditions only experience a runout increase from 2.53 to $2.86 \mathrm{~m}(13 \%)$ as slope increases from 2 to $4^{\circ}$, while $0.93-0$ $0 U_{\text {mf_st }}$ conditions undergo increases of 2.88 to $3+\mathrm{m}(\geq 6 \%)$. Slope angle is thus a secondary control on runout distance compared to aeration state. Only in one condition (-0.4-0.4$0.4 U_{\text {mf_st }}$ ) does increasing the slope from 2 to $4^{\circ}$ increase the runout distance by more than $50 \%$ (1.3 to $2 \mathrm{~m}$ ), whereas on a $2^{\circ}$ slope, increasing aeration from zero to just 0.4-0.4-0.4 $U_{\mathrm{mf} \text { st }}$ results in a $120 \%$ increase in runout distance $(0.59$ to $1.3 \mathrm{~m})$. Increasing this to the maximum aeration state used, 0.93-0.93-0 $U_{\mathrm{mf} \text { st, }}$ gives a further increase in runout distance of $122 \%$ (1.3 to $2.88 \mathrm{~m})$.

\section{Current behaviour and deposition}

Regardless of aeration state, all of the experimental currents appear unsteady. This is manifested in the transport of the particles as a series of pulses. Pulses are not always laterally 
Flume section Example deposit profiles

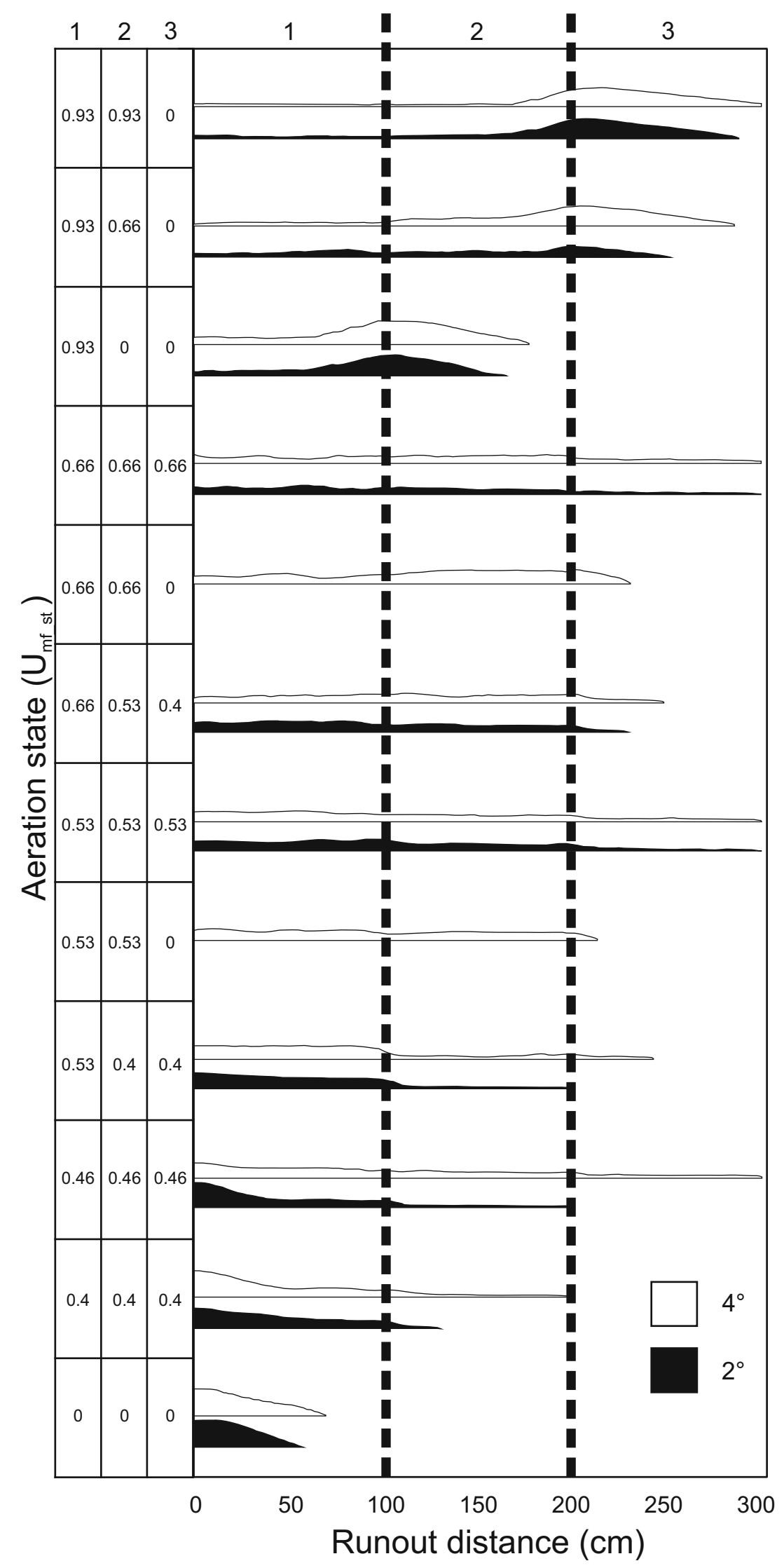


Fig. 3 Plots showing front velocity as each current propagates past the distance intervals $0.8-1.7 \mathrm{~m}$, on a $4^{\circ}$ channel slope. Note that where a profile stops on the $\mathrm{x}$-axis, this does not necessarily mean the current has halted; in some cases, it represents where the current front has become too thin to accurately track. Dividing line shows the transition between the first and second chambers along the flume. The aeration states (in $U_{\text {mf_st }}$ ) of a current in the first two chambers are given in the legend. a Plots for currents which experience a high and uniform, or near-uniform, gas supply from chamber 1 into chamber 2 , whereas b plots results for currents which experience a low and uniform gas supply, or a lower gas supply into chamber 2 than chamber 1 , which encourages de-aeration
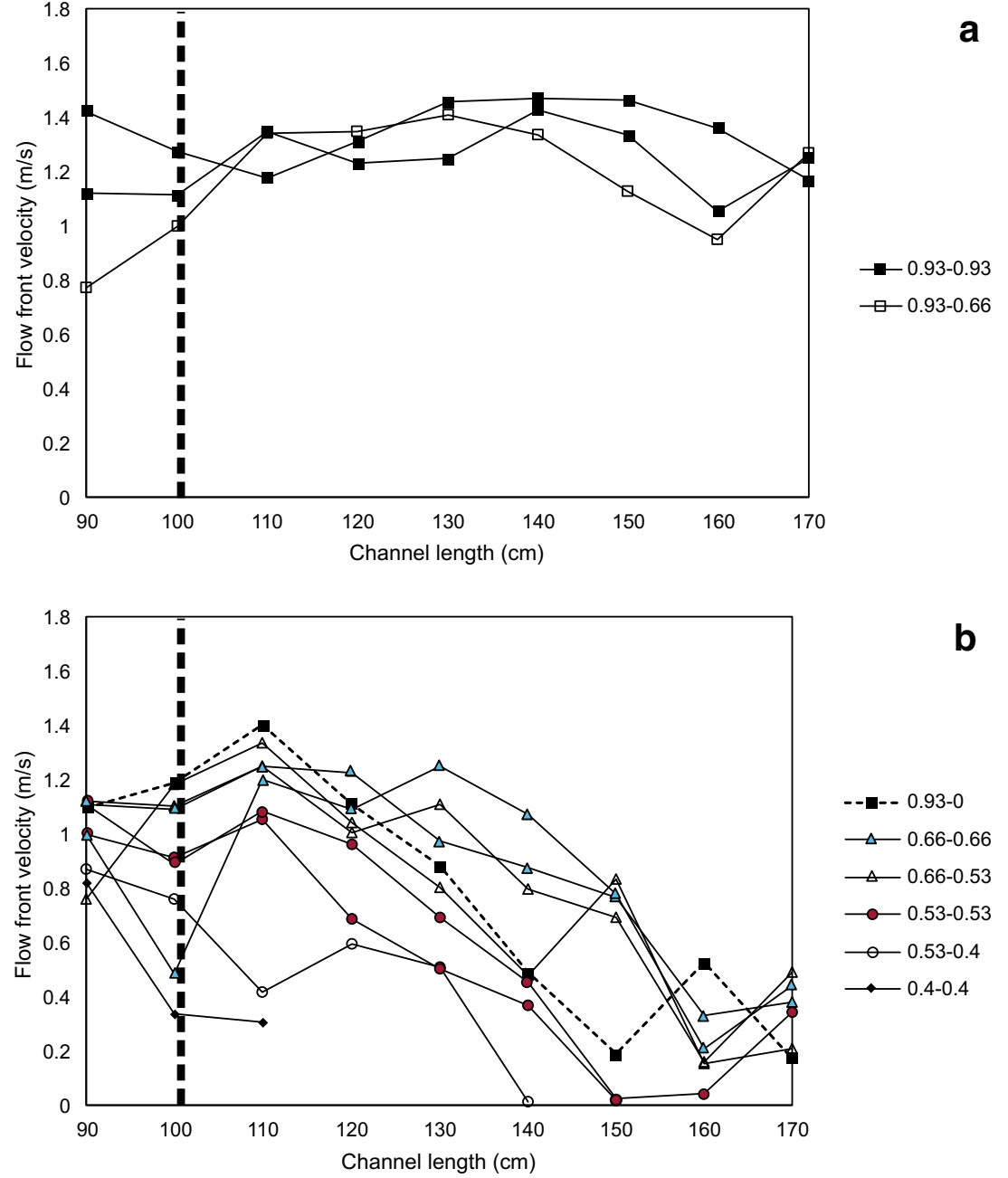

continuous down current, where slower, thinner pulses at the current front are overtaken by faster, thicker pulses. This can partly be seen in the waxing and waning of the velocity profiles in Fig. 3; some of the fluctuations in current front velocity are caused by a faster current pulse reaching the front of the current (Fig. 4). However, in most cases, overtaking of the flow front by a pulse happens outside the area of the highspeed camera and appears to be triggered by the current front slowing as it transitions into a less aerated chamber.

There appears to be five different groups of deposit morphology types generated by the various combinations of aeration states and slope angles (Table 2):

- Large aeration decrease - In cases where the current front passes into an unaerated chamber from a chamber that is aerated at $0.93 U_{\mathrm{mf} \text { st }}$, the resulting deposit is mostly confined to the unaerated chamber and has a wedge shape, with its thickest point being at the transition between the highly aerated and completely unaerated chambers. Such behaviour is also seen in the aeration state 0.93-0.66-0 $U_{\text {mf st }}$, and most clearly on a $4^{\circ}$ slope.
- Uniform aeration - Where all three chambers are aerated at $0.53 U_{\text {mf st }}$ or more, the current reaches the end of the flume. Except for currents passing through all chambers at

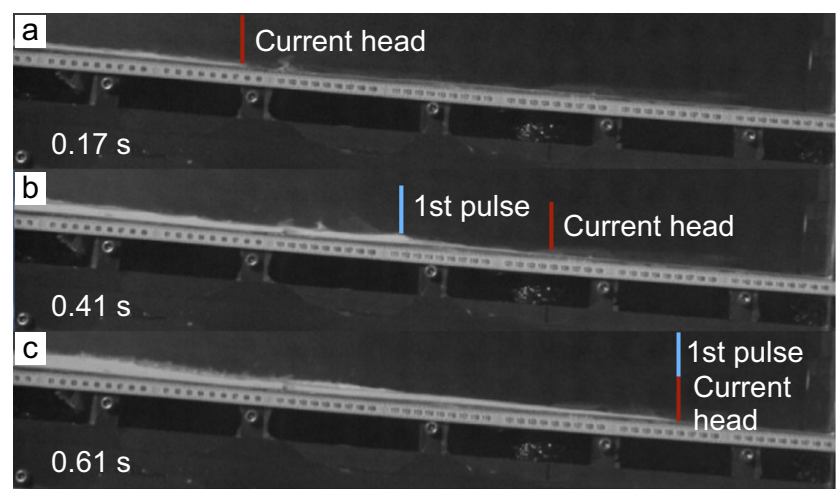

Fig. 4 High-speed video frames of an experimental current on a $4^{\circ}$ slope under 0.93-0-0 $U_{\mathrm{mf} \_s t}$ conditions (Fig. 2). Numbers on left are time in seconds since the current front entered the frame. a The front of the current enters the frame. $\mathbf{b}$ The current front continues to run out as the first pulse catches and begins to override it. c The current front is completely overtaken by the first pulse. A video of this experiment is presented in Online Resource 1 
Table 2 Groups of deposit types and the aeration states and slope angles which form them

\begin{tabular}{|c|c|c|c|}
\hline Deposit group & Flow conditions & Aeration State ( $\left.\mathbf{U}_{\text {mf_st }}\right)$ & Example profile \\
\hline \multirow[b]{2}{*}{$\begin{array}{c}\text { Thick downstream } \\
\text { wedge }\end{array}$} & \multirow[b]{2}{*}{ Large aeration decrease } & $0.93-0.93-0$ & \\
\hline & & $\begin{array}{c}0.93-0-0 \\
0.93-0.66-0\left(4^{\circ}\right)\end{array}$ & \\
\hline \multirow{2}{*}{$\begin{array}{l}\text { Even thickness but } \\
\text { thin in third chamber }\end{array}$} & \multirow[b]{2}{*}{ Uniform aeration } & $0.66-0.66-0.66$ & \\
\hline & & $\begin{array}{c}0.53-0.53-0.53 \\
0.46-0.46-0.46\left(4^{\circ}\right)\end{array}$ & \\
\hline \multirow[b]{2}{*}{ Even thickness } & \multirow[b]{2}{*}{$\begin{array}{l}\text { Moderate - low } \\
\text { aeration decrease }\end{array}$} & $0.93-0.66-0\left(2^{\circ}\right)$ & \\
\hline & & $\begin{array}{l}0.66-0.66-0 \\
0.53-0.53-0 \\
0.66-0.53-0.4\end{array}$ & \\
\hline $\begin{array}{l}\text { Centre of mass inside } \\
\text { first chamber }\end{array}$ & Low uniform aeration & $\begin{array}{c}0.53-0.4-0.4 \\
0.4-0.4-0.4 \\
0.46-0.46-0.46\left(2^{\circ}\right)\end{array}$ & \\
\hline Flat-topped wedge & Unaerated & $0-0-0$ & \\
\hline
\end{tabular}

$0.66 U_{\text {mf st }}$, the currents forming these deposits experience stalling of the current front, which then progresses at a much slower velocity while local thickening along the body of the current results in deposition upstream. The section of the deposit in the third chamber is usually noticeably thinner than in the first two chambers, which tends to be of an even thickness. Such deposits are also formed by $0.46-0.46-0.46 U_{\text {mf st }}$ currents on a $4^{\circ}$ slope.

- Moderate-low aeration decrease -Where the gas fluxes in the first two chambers are at $0.66 U_{\mathrm{mf}_{\text {_st }}}$ or $0.53 U_{\mathrm{mf} \_\mathrm{st}}$, but there is no (or low) flux in the third, the deposits formed are of approximately even thicknesses, with their leading edges inside the third chamber. This group also includes deposits formed under $0.93-0.66-0 U_{\mathrm{mf} s \mathrm{st}}$ conditions on a $2^{\circ}$ slope.

- Low uniform aeration-Where the second and third chambers are aerated at $0.46 U_{\mathrm{mf}}$ st or less, and the first

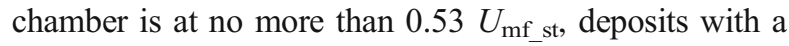
centre of mass located inside the first chamber form. Beyond this, the deposit thicknesses decreases rapidly.
- Unaerated -Under no aeration whatsoever, deposits form flat-topped wedges. These show angles steeper than the wedges in other groups.

\section{Discussion}

\section{Runout distance}

Once the current is fluidised or aerated, it is able to travel further than dry granular currents, as seen in previous experiments (e.g. Roche et al. 2004; Girolami et al. 2008; Roche 2012; Chédeville and Roche 2014; Rowley et al. 2014; Montserrat et al. 2016). This is because the increased pore pressures reduce frictional forces between the particles in the current, thus increasing mobility. However, here, we find that the relationship between aeration state and runout distance is not a simple correlation between 
higher gas fluxes and greater runout distances. A current with high initial aeration rates followed by a rapid decline does not travel as far as a current that is moderately aerated across a greater distance. For example, a current run with 0.93-0-0 $U_{\mathrm{mf} \text { st }}$ conditions does not travel as far as runs with conditions set at $0.66-0.66-0.66 U_{\text {mf_st }}$ or $0.53-0.53-$ $0.53 U_{\text {mf st }}$ (Fig. 2).

A highly aerated current may continue for some distance after passing into an unaerated chamber. Where only the first two chambers are aerated, this distance is dependent on the magnitude of the aeration state of the first chamber. For example, a current under 0.93-0.66-0 $U_{\mathrm{mf} \text { st }}$ conditions travels up to $24 \%$ further than one under 0.66-0.66-0 $U_{\text {mf_st }}$ conditions, but a current under 0.93$0.93-0 U_{\text {mf st }}$ conditions only travels up to $14 \%$ further than one under $0.93-0.66-0 U_{\text {mf_st }}$ conditions. However, a current that is moderately aerated for its entire passage can travel at least as far as those, which are initially highly aerated. This is a result of the high pore pressures being sustained across a greater portion of the current, simulating the long-lived high pore pressures of much thicker natural PDCs. Where a current passes into an unaerated chamber, the pore pressure diffusion time is dependent on the current thickness, current permeability, and the present pore pressure magnitude. As many current fronts are of similar thickness when they pass into an unaerated chamber, de-aeration seems to be controlled largely by the aeration state of the chambers prior to the unaerated one. A current with a lower aeration state will reach a completely de-aerated state and halt sooner than a current with a higher aeration state. This has implications for both runout distance and deposit characteristics.

\section{Velocity}

Higher initial gas velocities sustain higher current front velocities for greater distances, as seen in Fig. 3, where the 0.93-0.93-0 $U_{\text {mf_st }}$ and 0.93-0.66-0 $U_{\text {mf_st }}$ current velocity profiles sustain current front velocities of $>1 \mathrm{~m} / \mathrm{s}$ across the measured interval, in contrast to the other aeration states, where current front velocities rapidly fall below $1 \mathrm{~m} / \mathrm{s}$. High gas fluxes sustain high pore pressures, decreasing frictional forces between particles, reducing deceleration relative to less aerated currents. As the rate of pore pressure diffusion becomes greater than the supply of new gas to the current, it undergoes an increase in internal frictional forces and a consequent decrease in velocity.

When a current crosses into a chamber with a lower aeration state, this results in the lowering of its current front velocity (Fig. 3), although this change does not immediately take place and the current front may even accelerate as it crosses the boundary (as seen in many profiles in Fig. 3). The only currents which immediately decelerate in all cases are those where the aeration state of both chambers is 0.53 $U_{\mathrm{mf} \text { st }}$ or less. The temporary acceleration seen in the other currents mostly occurs over a distance of $\sim 10 \mathrm{~cm}$. Over this distance, these currents have sufficient momentum that the decreasing gas velocity and consequent increase in internal frictional forces do not immediately take effect. This is in line with our knowledge of pore pressure diffusion in PDCs - mostly composed of fine ash. In such cases, the pore pressure does not instantly diffuse due to the low permeability of the material (Druitt et al. 2007). In our experimental currents, passing into a lower or non-aerated chamber does not cause the current to immediately lose pore pressure (Fig. 3), but the magnitude of the difference in gas velocities between the chambers does influence the depositional behaviour of the current.

\section{The influence of slope angle}

The effects of slope angle on both dam-break type initially fluidised (Chédeville and Roche 2015) and dry granular currents (Farin et al. 2014) are relatively well known. However, the influence of varying slope angle for currents possessing sustained pore pressures is largely unquantified. Although only two $\left(2^{\circ}\right.$ and $\left.4^{\circ}\right)$ slope angles were examined, there is a clear effect on both current runout distance and current front velocity. Runout distance may be increased by up to $50 \%$, and higher current front velocities are sustained for greater distances on a steeper slope. The influence of small changes of slope on PDC dynamics is important because in nature low slope angles can be associated with PDC runout distances > $100 \mathrm{~km}$ (Valentine et al. 1989; Wilson et al. 1995).

The effect of slope angle on runout distance is most apparent when aeration is sustained over the whole current. Where the current front comes to a halt in an unaerated chamber, the runout distance increases no more than $13 \%$ on a $4^{\circ}$ slope compared to a $2^{\circ}$ slope. However, the overall effect of slope angle on the runout distance of sustained, moderate-to-highly aerated currents is difficult to quantify using our flume as such runs commonly move out of the flume.

\section{Propagation and deposit formation}

These experimental currents travel as a series of pulses generated by inherent unsteadiness developed during current propagation. Froude numbers $\left(\mathrm{Fr}=\frac{U}{(\mathrm{gH})^{\frac{1}{2}}}\right.$, where $U$ is the current front or pulse velocity) were determined for a number of current fronts and pulses by plotting the current front or pulse velocity as a function of $(g H)^{\frac{1}{2}}$ (Fig. 5). The slope of line of best fit gives 


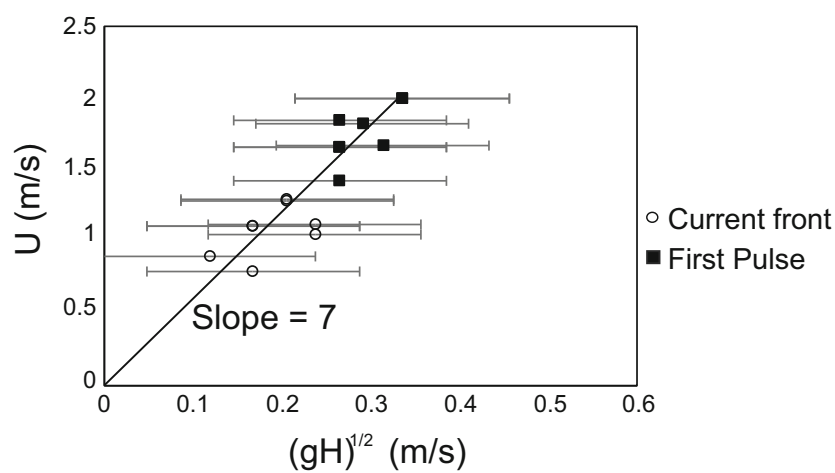

Fig. 5 Froude number for the fronts and first pulses of selected experimental currents. Uncertainties in velocity are smaller than the size of the symbols. Uncertainties in current height are relatively large due to the thinness of the current fronts relative to video resolution

$F r=7$, which fits with anticipated supercritical flow conditions (Gray et al. 2003). This is higher that the $F r$ of 2.58 obtained by Roche et al. (2004), likely due to the higher energy initiation and sustained nature of our currents compared to the depletive, dam-break currents of Roche et al. (2004).

The currents form a range of depositional structures depending on the flow dynamics and can deposit, through aggradation, much thicker deposits than the currents themselves. Our observations that the currents are both unsteady and can consist of a series of pulses suggest that deposition is occurring by stepwise aggradation (Branney and Kokelaar 1992; Sulpizio and Dellino 2008). The deposits produced in the experiments form five different groups, from which the following three important observations can be made: First, where the current front moves from an aerated chamber into an unaerated one, the shape and thickness of the deposit appear to depend on the magnitude of the drop in aeration state. Where the drop is high ( $0.93 U_{\text {mf_st }}$ and $0.66 U_{\text {mf_st }_{\text {st }}}$ to unaerated), a thick ( $\sim \times 10$ current thickness) wedge forms downstream, thickening mainly through retrogradational deposition as the high aeration states of the first two chambers quickly deliver the current body into the growing wedge. Second, sustained flow can build a deposit of relatively even thickness behind a stalling current front as inferred by Williams et al. (2014). Third, flat-topped wedges form where currents are dry, and runout distance is therefore affected only by channel slope angle. Overall, these observations suggest that a decrease in aeration state may be an important control on deposit formation, character, and distribution. These experiments provide a first attempt to directly control de-aeration in dense granular PDC analogues and greatly simplify the system, providing three relatively uniformly aerated segments of flow. This is in contrast to the high degree of spatial and temporal variation that might be envisaged in PDCs and the more gradual degassing a natural current will experience. We stress that the de-aeration rates observed in these experiments are faster than we would anticipate in natural PDCs; the sustained gas pore pressure provided here is applied so as to overcome the very rapid pore pressure diffusion timescales found in laboratory flows (Druitt et al. 2007; Rowley et al. 2014). This is due to the similarity of their bulk grain size to the ash found in PDCs, but much thinner flow thicknesses and hence more rapid pore pressure diffusion. Nevertheless, the decreases in aeration observed in some of our experimental flows have relevance for PDCs, which may experience, for example, a loss of fines or undergo temperature drops, thinning, and/ or the entrainment of courser material, all of which would act to de-aerate the current (e.g. Bareschino et al. 2007; Druitt et al. 2007; Gueugneau et al. 2017).

\section{Implications for future work}

We have demonstrated that variable aeration states in conjunction with slope angle can affect the shape and location of an experimental current's deposit. It seems logical to assume that these different types of deposit aggrade differently and so have different internal architectures, which may be analogous to features seen in ignimbrites. However, the internal architectures of these experimental deposits are hidden due to the uniform colour and grain size of the particles used. In future work, the use of dyed particles or particles of a different size would help identify the internal features of these deposits.

\section{Conclusions}

These experiments examined granular currents emplaced along inclined slopes, which possessed long-lived pore pressures under two conditions: (1) pore pressures which decreased down-current and (2) pore pressures which were uniform throughout the current. The flume configuration allowed the simulation of different aeration states within the currents, in order to simulate the dynamics and heterogeneous nature of pore pressure in PDCs. We examined the effects of varying combinations of aeration states, as well as the effect of slope angle on flow field dynamics and deposit characteristics.

It is clear that, in a general sense, higher gas fluxes (i.e. higher pore pressures) in the flume chambers result in greater runout distances. However, moderate $(0.53$ $\left.U_{\text {mf st }}-0.66 U_{\text {mf st }}\right)$ sustained gas fluxes produce at least equal runouts to high $\left(0.93 U_{\mathrm{mf} \text { st }}\right)$ initial fluxes that are 
subsequently declined. Similarly, high fluxes sustain higher current front velocities for greater distances, and currents may travel for $0.1-0.2 \mathrm{~m}$ after experiencing a decrease in gas flux supplied to their base before undergoing the consequent decrease in current front velocity.

Slope angle variation between $2^{\circ}$ and $4^{\circ}$ has a measurable impact on current runout distance, resulting in increases of between 0.11 and $1 \mathrm{~m}$ (i.e. $7->50 \%$ ), with greater increases occurring when low $\left(0.4 U_{\mathrm{mf} \_s t}-0.46 U_{\mathrm{mf} \_s t}\right)$ levels of aeration are sustained for the whole runout distance of the current. A higher slope angle also sustains higher current front velocities for greater distances.

The experimental currents travel as a series of supercritical pulses $(F r=7)$ which come to a relatively rapid halt, supporting the model of stepwise aggradation for dense basal currents (e.g. Schwarzkopf et al. 2005; Sulpizio and Dellino 2008; Charbonnier and Gertisser 2011; Macorps et al. 2018). Our findings also demonstrate intricate links between the overall current dynamics and the deposit morpho logy characteristics, with thicker, more confined deposits aggrading rapidly, where the current transitions from a high aeration state to lower aeration states. Such behaviour may be seen in natural PDCs subject to processes which result in de-aeration, such as temperature drops and/or loss of fines.

Acknowledgements We thank Andrew Harris, Richard Brown, and two anonymous reviewers, whose comments and suggestions significantly improved this manuscript.

Funding information This work was carried out as part of a $\mathrm{PhD}$ project funded by a University of Hull $\mathrm{PhD}$ scholarship in the Catastrophic Flows Research Cluster. Experiments were performed in the Geohazards Lab at the University of Portsmouth, using equipment funded by a British Society for Geomorphology Early Career Researcher Grant held by PR.

\section{Appendix 1. Grain size data}

Table 3 Grain size data and statistics for the particles used in the experiments. Six samples were taken from across the material batch and subjected to particle size analysis using a QICPIC

\begin{tabular}{|c|c|c|c|c|c|c|}
\hline Sample & Run & Median diameter $(\mu \mathrm{m})$ & Mean $(\mu \mathrm{m})$ & Squared difference & Variance & Standard deviation \\
\hline \multirow[t]{3}{*}{1} & 1 & 64.4 & & 0.7 & & \\
\hline & 2 & 63.2 & 63.9 & 0.5 & 0.3 & 0.5 \\
\hline & 3 & 64.1 & & 0.1 & & \\
\hline \multirow[t]{3}{*}{2} & 1 & 65.4 & & 0.3 & & \\
\hline & 2 & 65.6 & 66.0 & 0.2 & 0.5 & 0.7 \\
\hline & 3 & 67.0 & & 1.0 & & \\
\hline \multirow[t]{3}{*}{3} & 1 & 59.9 & & 3.6 & & \\
\hline & 2 & 62.6 & 61.8 & 0.5 & 1.9 & 1.4 \\
\hline & 3 & 63.0 & & 1.4 & & \\
\hline \multirow[t]{3}{*}{4} & 1 & 58.2 & & 0.6 & & \\
\hline & 2 & 58.7 & 59.0 & 0.1 & 0.7 & 0.8 \\
\hline & 3 & 60.1 & & 1.3 & & \\
\hline \multirow[t]{3}{*}{5} & 1 & 53.4 & & 11.0 & & \\
\hline & 2 & 49.7 & 50.0 & 0.2 & 6.6 & 2.6 \\
\hline & 3 & 47.1 & & 8.6 & & \\
\hline \multirow[t]{3}{*}{6} & 1 & 48.4 & & 9.2 & & \\
\hline & 2 & 44.3 & 45.4 & 1.1 & 4.8 & 2.1 \\
\hline & 3 & 43.4 & & 4.0 & & \\
\hline \multirow[t]{3}{*}{7} & 1 & 65.4 & & 0.2 & & \\
\hline & 2 & 65.7 & 64.9 & 0.5 & 0.8 & 0.9 \\
\hline & 3 & 63.7 & & 1.5 & & \\
\hline \multirow[t]{3}{*}{8} & 1 & 69.1 & & 1.3 & & \\
\hline & 2 & 67.3 & 67.9 & 0.3 & 0.7 & 0.8 \\
\hline & 3 & 67.3 & & 0.3 & & \\
\hline
\end{tabular}


Open Access This article is distributed under the terms of the Creative Commons Attribution 4.0 International License (http:// creativecommons.org/licenses/by/4.0/), which permits unrestricted use, distribution, and reproduction in any medium, provided you give appropriate credit to the original author(s) and the source, provide a link to the Creative Commons license, and indicate if changes were made.

\section{References}

Andrews B, Manga M (2011) Effects of topography on pyroclastic density current runout and formation of coignimbrites. Geology 39 : 1099-1102. https://doi.org/10.1130/G32226.1

Andrews B, Manga M (2012) Experimental study of turbulence, sedimentation and coignimbrite mass partitioning in dilute pyroclastic density currents. J Volcanol Geotherm Res 225-226:30-44. https:// doi.org/10.1016/j.jvolgeores.2012.02.011

Bareschino P, Gravina T, Lirer L, Marzocchella A, Petrosino P, Salatino P (2007) Fluidization and de-aeration of pyroclastic mixtures: the influence of fines content, polydispersity and shear flow. J Volcanol Geotherm Res 164:284-292. https://doi.org/10.1016/j.jvolgeores. 2007.05.013

Brand B, Bendaña S, Self S, Pollock N (2016) Topographic controls on pyroclastic density current dynamics: insight from 18 May 1980 deposits at Mount St. Helens, Washington (USA). J Volcanol Geotherm Res 321:1-17. https://doi.org/10.1016/j.jvolgeores.2016.04.018

Branney MJ, Kokelaar P (1992) A reappraisal of ignimbrite emplacement: progressive aggradation and changes from particulate to non-particulate flow during emplacement of high grade ignimbrite. Bull Volcanol 54:504-520. https://doi.org/10.1007/BF00301396

Branney MJ, Kokelaar P (2002) Pyroclastic density currents and the sedimentation of ignimbrites. Geol Soc Lond Memoir 27:7-21. https://doi.org/10.1144/GSL.MEM.2003.027.01.02

Breard ECP, Lube G (2016) Inside pyroclastic density currentsuncovering the enigmatic flow structure and transport behaviour in large-scale experiments. Earth Planet Sci Lett 458:22-36. https:// doi.org/10.1016/j.epsl.2016.10.016

Breard ECP, Lube G, Jones JR, Dufek J, Cronin SJ, Valentine G, Moebis A (2016) Coupling of turbulent and non-turbulent flow regimes within pyroclastic density currents. Nat Geosci 9:767-771. https:// doi.org/10.1038/ngeo2794

Breard ECP, Dufek J, Lube G (2018) Enhanced mobility in concentrated pyroclastic density currents: an examination of a self-fluidization mechanism. Geophys Res Lett 45:654-664. https://doi.org/10. 1002/2017GL075759

Brown MC (1962) Nuées ardentes and fluidization. Am J Sci 260:467470. https://doi.org/10.2475/ajs.260.6.467

Brown RJ, Branney MJ (2004) Bypassing and diachronous deposition from density currents: evidence from a giant regressive bed form in the Poris ignimbrite, Tenerife, Canary Islands. Geology 32:445448. https://doi.org/10.1130/G20188.1

Burgissier A, Bergantz GW (2002) Reconciling pyroclastic flow and surge: the multiphase physics of pyroclastic density currents. Earth Planet Sci Lett 202:405-418. https://doi.org/10.1016/S0012821X(02)00789-6

Cas RAF, Wright HMN, Folkes CB, Lesti C, Porreca M, Giordano G, Viramonte JG (2011) The flow dynamics of an extremely large volume pyroclastic flow, the 2.08-Ma Cerro Galán Ignimbrite, NW Argentina, and comparison with other flow types. Bull Volcanol 73: 1583-1609. https://doi.org/10.1007/s00445-011-0564-y

Charbonnier SJ, Gertisser R (2011) Deposit architecture and dynamics of the 2006 block-and-ash flows of Merapi Volcano, Java, Indonesia. Sedimentology 58:1573-1612. https://doi.org/10.1111/j.1365-3091. 2011.01226.x
Chédeville C, Roche O (2014) Autofluidization of pyroclastic flows propagating on rough substrates as shown by laboratory experiments. J Geophys Res Solid Earth 119:1764-1776. https://doi.org/ 10.1002/2013JB010554

Chédeville C, Roche O (2015) Influence of slope angle on pore pressure generation and kinematics of pyroclastic flows: insights from laboratory experiments. Bull Volcanol 77:1-13. https://doi.org/10.1007/ s00445-015-0981-4

Dade WB, Huppert HE (1996) Emplacement of the Taupo ignimbrite by a dilute turbulent flow. Nature 381:509-512. https://doi.org/10.1038/ $385307 \mathrm{a} 0$

Douillet GA, Pacheco DA, Kueppers U, Letort J, Tsang-Hin-Sun È, Bustillos J, Hall M, Ramón P, Dingwell DB (2013) Dune bedforms produced by dilute pyroclastic density currents from the August 2006 eruption of Tungurahua volcano, Ecuador. Bull Volcanol 75: 762. https://doi.org/10.1007/s00445-013-0762-x

Druitt TH (1992) Emplacement of the 18 May 1980 lateral blast deposit ENE of Mount St. Helens, Washington. Bull Volcanol 54:554-572. https://doi.org/10.1007/BF00569940

Druitt TH (1995) Settling behaviour of concentrated dispersions and some volcanological applications. J Volcanol Geotherm Res 65: 27-39. https://doi.org/10.1016/0377-0273(94)00090-4

Druitt TH, Sparks RSJ (1982) A proximal ignimbrite breccia facies on Santorini, Greece. J Volcanol Geotherm Res 13:147-171. https:// doi.org/10.1016/0377-0273(82)90025-7

Druitt TH, Calder ES, Cole PD, Hoblitt RS, Loughlin SC, Norton GE, Ritchie R, Sparks SJ, Voight B (2002) Small-volume, highly mobile pyroclastic flows formed by rapid sedimentation from pyroclastic surges at Soufrière Hills Volcano, Montserrat: an important volcanic hazard. In: Druitt TH, Kokelaar BP (eds). The eruption of Soufrière Hills Volcano, Montserrat, from 1995 to 1999. Geol Soc London Memoir, 21, pp 263-279. https://doi.org/10.1144/GSL.MEM.2002.021.01.12

Druitt TH, Avard G, Bruni G, Lettieri P, Maez F (2007) Gas retention in fine-grained pyroclastic flow materials at high temperatures. Bull Volcanol 69:881-901. https://doi.org/10.1007/s00445-007-0116-7

Eames I, Gilbertson M (2000) Aerated granular flow over a horizontal rigid surface. J Fluid Mech 424:169-195. https://doi.org/10.1017/ S0022112000001920

Farin M, Mangeney A, Roche O (2014) Fundamental changes of granular flow dynamics, deposition, and erosion processes at high slope angles: insights from laboratory experiments. J Geophys Res Earth 119:504-532. https://doi.org/10.1002/ 2013JF002750

Fenner CN (1923) The origin and mode of emplacement of the great tuff deposit in the Valley of Ten Thousand Smokes. National Geographic Society Contributed Technical Papers, Katmai Series, 1:1

Fierstein J, Hildreth W (1992) The plinian eruptions of 1912 at Novarupta, Katmai National Park, Alaska. Bull Volcanol 54:646684. https://doi.org/10.1007/BF00430778

Geldart D (1973) Types of gas fluidization. Powder Technol 7:285-292. https://doi.org/10.1016/0032-5910(73)80037-3

Gibilaro LG, Gallucci K, Di Felice R, Pagliai P (2007) On the apparent viscosity of a fluidized bed. Chem Eng Sci 62:294-300. https://doi. org/10.1016/j.ces.2006.08.030

Gilbertson MA, Jessop DE, Hogg AJ (2008) The effects of gas flow on granular currents. Philos Trans R Soc A 366:2191-2203. https://doi. org/10.1098/rsta.2007.0021

Girolami L, Druitt TH, Roche O, Khrabrykh Z (2008) Propagation and hindered settling of laboratory ash flows. J Geophys Res Solid Earth 113:B02202. https://doi.org/10.1029/2007JB005074

Gray JMNT, Tai Y-C, Noelle S (2003) Shock waves, dead zones and particle-free regions in rapid granular free-surface flows. J Fluid Mech 291:161-181. https://doi.org/10.1017/S0022112003005317

Gueugneau V, Kelfoun K, Roche O, Chupin L (2017) Effects of pore pressure in pyroclastic flows: numerical simulation and 
experimental validation. Geophys Res Lett 44:2194-2202. https:// doi.org/10.1002/2017GL072591

Iverson RM (1997) The physics of debris flows. Rev Geophys 35:245296. https://doi.org/10.1029/97RG00426

Li L, Ma W (2011) Experimental study on the effective particle diameter of a packed bed with non-spherical particles. Transp Porous Media 89:35-48. https://doi.org/10.1007/s11242-011-9757-2

Macorps E, Charbonnier SJ, Varley NR, Capra L, Atlas Z, Cabré J (2018) Stratigraphy, sedimentology and inferred flow dynamics from the July 2015 block-and-ash flow deposits at Volcán de Colima, Mexico. J Volcanol Geotherm Res 349:99-116. https://doi.org/10. 1016/j.jvolgeores.2017.09.025

McTaggart KC (1960) The mobility of nuées ardentes. Am J Sci 258: 369-382. https://doi.org/10.2475/ajs.258.5.369

Montserrat S, Tamburrino A, Roche O, Niño Y (2012) Pore fluid pressure diffusion in defluidizing granular columns. J Geophys Res 117: F02034. https://doi.org/10.1029/2011JF002164

Montserrat S, Tamburrino A, Roche O, Niño Y, Ihle CF (2016) Enhanced run-out of dam-break granular flows caused by initial fluidization and initial material expansion. Granul Matter 18:1-9. https://doi.org/ 10.1007/s10035-016-0604-6

Roche O (2012) Depositional processes and gas pore pressure in pyroclastic flows: an experimental perspective. Bull Volcanol 74:18071820. https://doi.org/10.1007/s00445-012-0639-4

Roche O, Gilbertson MA, Phillips JC, Sparks RSJ (2002) Experiments on deaerating granular flows and implications for pyroclastic flow mobility. Geophys Res Lett 29:40-1-40-4. https://doi.org/10.1029/ 2002GL014819

Roche O, Gilbertson MA, Phillips JC, Sparks RSJ (2004) Experimental study of gas-fluidized granular flows with implications for pyroclastic flow emplacement. J Geophys Res Solid Earth 109:B10201. https://doi.org/10.1029/2003JB002916

Roche O, Montserrat S, Niño Y, Tamburrino A (2010) Pore fluid pressure and internal kinematics of gravitational laboratory air-particle flows: insights into the emplacement dynamics of pyroclastic flows. J Geophys Res Solid Earth 115:B12203. https://doi.org/10.1029/ 2009JB007133

Roche O, Niño Y, Mangeney A, Brand B, Pollock N, Valentine GA (2013) Dynamic pore-pressure variations induce substrate erosion by pyroclastic flows. Geology 41:1107-1110. https://doi.org/10. 1130/G34668.1

Roche O, Buesch DC, Valentine GA (2016) Slow-moving and fartravelled dense pyroclastic flows during the Peach Spring supereruption. Nat Commun 7:10890. https://doi.org/10.1038/ ncomms 10890

Rowley PD, MacLeod NS, Kuntz MA, Kaplan AM (1985) Proximal bedded deposits related to pyroclastic flows of May 18, 1980, Mount St. Helens, Washington. Geol Soc Am Bull 96:13731383. https://doi.org/10.1130/0016-7606(1985)96<1373: PBDRTP $>2.0 . C O ; 2$

Rowley PJ, Roche O, Druitt TH, Cas R (2014) Experimental study of dense pyroclastic density currents using sustained, gas-fluidized granular flows. Bull Volcanol 76:855. https://doi.org/10.1007/ s00445-014-0855-1

Sarocchi D, Sulpizio R, Macias JL, Saucedo R (2011) The 17 July 1999 block-and-ash flow (BAF) at Colima Volcano: new insights on volcanic granular flows from textural analysis. J Volcanol Geotherm Res 204:40 56. https://doi.org/10.1016/j.jvolgeores.2011.04.013

Savage SB, Hutter K (1989) The motion of a finite mass of granular material down a rough incline. J Fluid Mech 199:177-215. https:// doi.org/10.1017/S0022112089000340

Schwarzkopf LM, Schmincke H-U, Cronin SJ (2005) A conceptual model for block-and-ash flow basal avalanche transport and deposition, based on deposit architecture of 1998 and 1994 Merapi flows. J Volcanol Geotherm Res 139:117-134. https://doi.org/10.1016/j. jvolgeores.2004.06.012

Sparks RSJ (1976) Grain size variations in ignimbrites and implications for the transport of pyroclastic flows. Sedimentology 23:147-188. https://doi.org/10.1111/j.1365-3091.1976.tb00045.x

Sparks RSJ (1978) Gas release rates from pyroclastic flows: an assessment of the role of fluidisation in their emplacement. Bull Volcanol 41:1-9. https://doi.org/10.1007/BF02597679

Sulpizio R, Dellino P (2008) Depositional mechanisms and pulsating behaviour of pyroclastic density currents. In: Marti L, Gottsman J (eds) Caldera volcanism: analysis, modelling and response. Developments in volcanology, vol 10. Elsevier, pp 57-96. https:// doi.org/10.1016/S1871-644X(07)00002-2

Valentine GA, Buesch DC, Fisher RV (1989) Basal layered deposits of the Peach Springs Tuff, northwestern Arizona, USA. Bull Volcanol 51:395-414. https://doi.org/10.1007/BF01078808

Walker GPL (1983) Ignimbrite types and ignimbrite problems. J Volcanol Geotherm Res 17:65-88. https://doi.org/10.1016/0377-0273(83)90062-8

Williams R, Branney MJ, Barry TL (2014) Temporal and spatial evolution of a waxing then waning catastrophic density current revealed by chemical mapping. Geology 42:107-110. https://doi.org/10.1130/G34830.1

Wilson CJN (1980) The role of fluidization in the emplacement of pyroclastic flows: an experimental approach. J Volcanol Geotherm Res 8: 231-249. https://doi.org/10.1016/0377-0273(80)90106-7

Wilson CJN (1985) The Taupo eruption, New Zealand: II. The Taupo Ignimbrite. Philos Trans R Soc A 314:229-310. https://doi.org/10. 1098/rsta.1985.0020

Wilson CJN (1997) Emplacement of Taupo ignimbrite. Nature 385:306307. https://doi.org/10.1038/385306a0

Wilson CJN, Walker GPL (1982) Ignimbrite depositional facies: the anatomy of a pyroclastic flow. J Geol Soc Lond 139:581-592. https:// doi.org/10.1144/gsjgs.139.5.0581

Wilson CJN, Houghton BF, Kamp PJJ, McWilliams MO (1995) An exceptionally widespread ignimbrite with implications for pyroclastic flow emplacement. Nature 378:605-607. https://doi.org/10.1038/378605a0

Yamamoto T, Takarada S, Suto S (1993) Pyroclastic flows from the 1991 eruption of Unzen volcano, Japan. Bull Volcanol 55:166-175. https://doi.org/10.1007/BF00301514 